\title{
IgM anti-GM1 antibody titers in patients with monomelic amyotrophy
}

\author{
Dinesh Khandelwal, Manvir Bhatia, S. Vivekanandan*, Sumit Singh, Garima Shukla, \\ Vinay Goyal, Madhuri Behari
}

Departments of Neurology and *Biochemistry, All India Institute of Medical Sciences, New Delhi - 110029, India

\begin{abstract}
Background: Monomelic amyotrophy (MMA) is a benign motor neuron disorder, which particularly affects young people and the etiology is still unknown. Gangliosides are located on the outer surface of motor neurons. Anti-GM1 antibodies have been found to be elevated in multi-focal motor neuropathy with conduction block and other neurological diseases, which may have therapeutic implication. Aim: To evaluate IgM anti-GM1 antibody titers in patients of monomelic amyotrophy. Setting and Design: prospective controlled study. Materials and Methods: Fortysix clinically and electrophysiologically diagnosed cases of MMA were assessed for IgM anti-GM1 antibody titers by enzyme-linked immunosorbent assay (ELISA) method and compared with titers in healthy controls, cases of amyotrophic lateral sclerosis (ALS) and acute inflammatory demyelinating polyneuropathy (AIDP). Titer of 800 units was taken as upper limit of normal (Buhlmann Laboratories AG, Switzerland). Statistical Analysis Used: one-way ANOVA. Results: The mean age of 46 patients with MMA was $24.5( \pm 7.3)$ years, with male female ratio of $44: 2$. The mean age of 19 healthy controls was $24.1( \pm 3)$ years with male: female ratio of $18: 1$. Five $(26 \%)$ individuals in the healthy control group, $22(48 \%)$ patients of MMA, four (30\%) of ALS and five (50\%) of AIDP had high titers of IgM antiGM1 antibody $(P>0.05)$. Conclusions: Although larger number of patients with MMA had higher IgM anti-GM1 antibody titers, the difference was not statistically significant from titers of healthy individuals, and of patients in the ALS and AIDP group.
\end{abstract}

Key words: GM1 gangliosides, Hirayama disease, monomelic amyotrophy

Gangliosides are sialic acid containing glycosphingolipids that are found in the outer surface of cell membranes. They are most abundant in the nervous system, where their functions include regulation of neuronal growth and development. ${ }^{[1]}$ GM1 epitope is present not only in motor neurons and axons but also in dorsal root ganglia and sensory axons. The antibodies to GM1 have attracted most attention, specially high titers of anti-GM1 antibodies in multi-focal motor neuropathy with conduction block. ${ }^{21}$ However, acute inflammatory demyelinating polyradiculoneuropathy (AIDP), chronic inflammatory demyelinating polyneuropathy (CIDP) and lower motor neuron disorders and neuropathies of unknown origin are also associated with raised antibodies to GM1 gangliosides. ${ }^{[3]}$ The frequent occurrences of high titers of anti-GM1 antibodies in motor neuropathies raised hope that serum testing in these patients would help in their diagnosis and treatment. There are a few reports of improvement with immunosuppressive or intravenous immunoglobulin (IVIg) treatments in patients with lower motor neuron syndromes. ${ }^{[4,5]}$

Monomelic amyotrophy (MMA) is also a lower motor neuron syndrome with characteristic features of wasting and weakness of muscles involving unilateral or asymmetrical upper limbs or unilateral lower limb. It usually occurs in young males and has a very benign course. ${ }^{[6]}$ The exact etiopathogenesis of this disorder is still unknown. ${ }^{[7,8]}$ There can be widespread electromyographic changes in patients with clinically focal disease and central motor conduction time remains unaffected. ${ }^{[9,10]}$ Review of the literature revealed only one such previous report in which anti-GM1 antibody had been evaluated in nine patients of MMA. ${ }^{[11]}$ Six of them had raised titers and three of these responded to IVIg or plasmapheresis. This study suggested that autoimmune etiopathogenesis could also be a possibility for MMA.

Based on these observations, the present study aimed to determine the frequency of IgM anti-GM1 antibodies in patients of MMA and to compare these values with those in patients with other neurological disorders, and of healthy subjects.

\section{Materials and Methods}

Patients of MMA who attended the outpatient department or were admitted to the neurology ward from September 2000 to 
September 2002 were enrolled in this study. Adolescents or adults with history of slowly progressive atrophy involving unilateral or asymmetrical upper limbs or lower limb for at least one-year duration without sensory and $\backslash$ or bladder symptoms and no evidence of structural lesion on magnetic resonance imaging (MRI) cervical spine were included. Patients with history of poliomyelitis, significant trauma to the spine or extremities, exposure to known toxins, vaccination in past six months, signs of pyramidal, extrapyramidal or sensory involvement, abnormal motor or sensory nerve conduction studies other than reduced amplitude or absent compound muscle action potential and an abnormal cervical (except mild cord atrophy) or lumbosacral spine MRI were excluded. A predesigned performa was filled for clinical and demographic details. Age-matched healthy individuals without evidence of any disease on clinical examination, and cases of ALS and AIDP diagnosed by the El Escorial and Asbury criteria respectively were taken as controls. Blood samples were collected from the patients at the time of first diagnosis of AIDP and ALS. Ethical clearance from the ethical committee and informed consent from all the patients and control group was taken.

\section{Electrophysiological evaluation}

In patients with MMA, electrophysiological evaluation including sensory and motor nerve conduction studies and minimal fwave latencies of at least one upper and lower limb according to standard techniques and needle electromyography of six muscles in three limbs which included the involved limb, the contralateral limb and one other limb, was done.

\section{Anti-GM1 antibodies assessment}

All the serum samples were kept at -20 degree centigrade. AntiGM1 antibodies were measured by enzyme-linked immunoassay (ELISA). The microtiter plates were precoated with monosialoganglioside $\mathrm{GM}_{1}$. All the samples were diluted 50 times with incubation buffer and left in ice for $30 \mathrm{~min}$ prior to use. Wells were washed with approximately $350 \mu$ well-refrigerated wash buffer and $100 \mu$ diluted samples and standards (800, 2400, 6000 and $15000 \mathrm{U}$ ) were pipetted into the wells (incubation buffer in blank). The plate was incubated for two hours at $2-8^{\circ} \mathrm{C}$ and after discarding the contents the wells were washed thrice with refrigerated wash buffer. Then $100 \mu$ l enzyme conjugate (IgM conjugated to horseradish peroxidase) was added and incubated for two hours at $2-8^{\circ} \mathrm{C}$. After washing the wells thrice with wash buffer, $100 \mu \mathrm{l}$ of TMB substrate (allowed to come to ambient temperature prior to use) was added to each well. The plate was covered properly to protect from light and incubated for $30 \mathrm{~min}$ at room temperature on a plate mixture with 800-1000 rpm. The reaction was stopped by $100 \mu \mathrm{l}$ of $0.25 \mathrm{M} \mathrm{H}_{2} \mathrm{SO}_{4}$ and the absorbance was read at $450 \mathrm{~nm}$. The blank value was subtracted from all readings and a standard graph was plotted using absorbance values of standards ( $\mathrm{Y}$ axis) and concentration in units (X axis) on a lin/log graph paper. The concentrations of the unknown samples were calculated using this standard graph.

Monosialo-ganglioside GM $\mathrm{GM}_{1}$, Standards, enzyme conjugate, were all supplied by Buhlmann Laboratories AG, Switzerland.

A cut-off value of 800 BTU was taken according to 3 SD results of 120 healthy individuals published in the kit. Higher than 800 BTU IgM anti-GM1 antibody titers were arbitrarily divided into three groups; Group 1 (mildly raised) with titers 800 to 1600 , Group 2 (moderately raised) with titers from 1600 to 3200 , and Group 3 (high) with titers more than 3200 [Table 1].

\section{Statistical analysis}

All data were entered in excel worksheet and descriptive data were calculated. Because of wide range of titers among patients and controls, log values were calculated and one-way ANOVA test was applied and $P$ value $<0.05$ was taken significant.

\section{Results}

There were total 46 patients of MMA with mean age of $24.5( \pm 7.3)$ years and male: female ratio of $44: 2$. There was bilateral distal wasting in $13(28 \%)$, unilateral distal involvement in $21(45 \%)$, proximal upper limb involvement in eight (17\%) and lower limb involvement in four $(8.5 \%)$ patients. The mean age of onset of atrophy was $20.4( \pm 5.7)$ years and mean duration of atrophy was $4.1( \pm 4.3)$ years.

These were compared with 19 healthy controls [mean age 24.1 $( \pm 3)$ years and male: female ratio of 18:1], 13 patients with AIDP [mean age 27.6 ( \pm 8.6) and male: female ratio of 11:2] and 10 male patients with ALS [mean age $41.1( \pm 6.6)]$. In healthy control group titers were normal in 14 (73\%), mildly raised in three $(16 \%)$ and moderately raised in two (10\%) individuals. In patients with MMA, titers were normal in 24 (52\%), mildly raised in 11 (24\%), moderately raised in nine (19\%) and high in two (4\%) patients. In patients with AIDP, titers were normal in nine (69\%), moderately raised in three $(32 \%)$ and high in one $(7 \%)$ patient and in patients with ALS, titers were normal in five (50\%), moderately raised in three $(30 \%)$ and high in two $(20 \%)$ patients [Table 1]. There was no statistically significant difference in the titers among these groups $(P>0.05)$, Figure 1 .

\begin{tabular}{|c|c|c|c|c|}
\hline IgM anti-GM1 titers BTU & Healthy controls $\mathrm{n}(\%)$ & MMA n (\%) & AIDP n (\%) & ALS n (\%) \\
\hline$<800$ (normal) & $14(73)$ & $24(52)$ & $9(69)$ & $5(50)$ \\
\hline $800-1600$ (mild) & $3(16)$ & $11(24)$ & 0 & 0 \\
\hline 1600-3200 (moderate) & $2(10)$ & $9(19)$ & $3(23)$ & $3(30)$ \\
\hline$>3200$ (high) & 0 & $2(4)$ & $1(7)$ & $2(20)$ \\
\hline Total & 19 & 46 & 13 & 10 \\
\hline
\end{tabular}

MMA: Monomelic amyotrophy, AIDP: Acute inflammatory polyradiculoneuropathy, ALS: Amyotrophic lateral sclerosis 


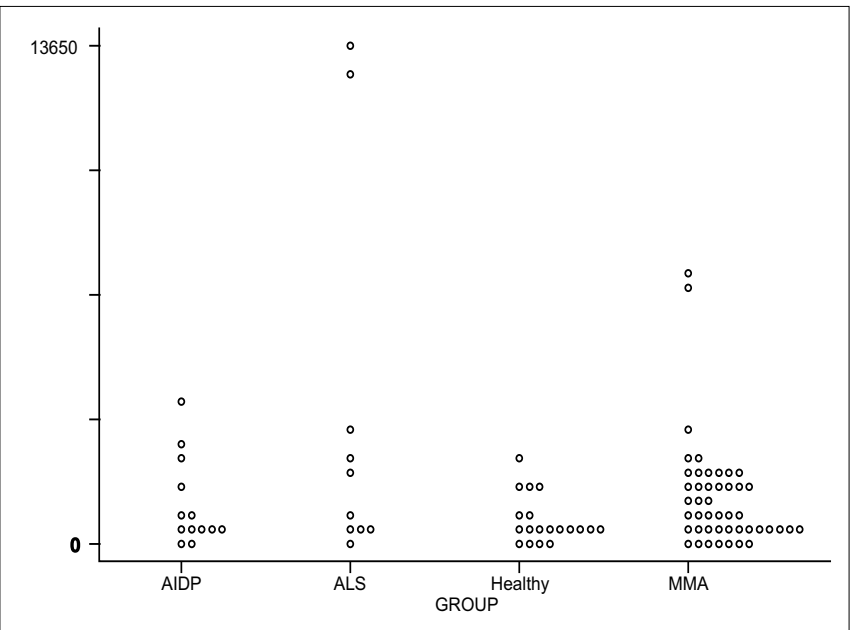

Figure 1: IgM anti GM1 antibody titers in patients and controls

\section{Discussion}

In the present study although a larger number of patients in the MMA group had higher IgM anti-GM1 antibody titers as compared to healthy controls, it was not statistically significant. In the only previous report of nine patients of MMA, IgG antiGM1 was elevated in six and three of them showed improvement with IVIg or cyclophosphamide. ${ }^{[1]}$ There are other reports of high IgM anti-GM1 antibody titers in patients of lower motor neuron disease. There are circumstantial evidences supporting the pathogenicity of anti-GM1 antibodies in these lower motor neuron diseases. Reports of clinical improvement in strength and falling serum anti-GM1 antibody titer in patients with lower motor neuron disease after immunomodulatory treatment are suggestive of their being contributory to the disease pathogenesis. ${ }^{[4,5]}$ Injection into rabbits with GM1 or some of earbohydrate moieties has produced an autoimmune neuropathy similar to multi-focal motor neuropathy. ${ }^{[12]}$ Antibodies in low titers may rise because of immune response to disease or as a part of nonspecific immune activation. Low titers of antiganglioside antibodies have been found in patients with other neurological illnesses like amyotrophic lateral sclerosis, multiple sclerosis and Alzheimer's disease and sometimes in healthy individuals. ${ }^{[13-15]}$ In some patients treatment with oral gangliosides has been associated with development of GuillainBarre syndrome. ${ }^{[16]}$ Therapeutic trial with IVIg or plasmapheresis in patients with MMA may further help to understand the role of theses antibodies. It is difficult to evaluate the significance of IgM anti-GM1 antibody titers in this study as patients presented in different stages of the disease and we could do only IgM antiGM1 antibodies. There was no clinical correlation of antibody titers.

\section{Conclusion}

Our results suggest that IgM anti-GM1 antibodies titers in patients of MMA are not significantly different from those of healthy controls or patients with ALS and AIDP.

\section{References}

1. Ledeen RW. Biology of gangliosides: Neuritogenic and neuronotrophic properties. J Neurosei Res 1984;12:147-59.

2. Pestronk A, Cornblath DR, Ilyas AA, Baba H, Quarles RH, Griffin JW, et al. A treatable multifocal motor neuropathy with antibodies to GM1 ganglioside. Ann Neurol 1988;24:73-8.

3. Sadiq SA, Thomas FP, Kilidireas K, Protopsaltis S, Hays AP, Lee KW, et al. The spectrum of neurologic disease associated with anti-GM1 antibodies. Neurology 1990;40:1067-72.

4. Pestronk A, Lopate G, Kornberg AJ, Elliott JL, Blume G, Yee WC, Goodnough LT. Distal lower motor neuron syndrome with high-titer serum IgM anti-GM1 antibodies: Improvement following immunotherapy with monthly plasma exchange and intravenous cyclophosphamide. Neurology 1994;44:2027-31

5. van den Berg LH, Franssen H, Van Doorn PA, Wokke JH. Intravenous immunoglobulin treatment in lower motor neuron disease associated with highly raised anti-GM1 antibodies. J Neurol Neurosurg Psychiatry 1997;63:674-7.

6. Gourie-Devi M, Nalini A. Long-term follow-up of 44 patients with brachial monomelic amyotrophy. Acta Neurol Scand 2003;107:215-20.

7. Misra UK, Kalita J.Central motor conduction in Hirayama disease Electroencephalogr Clin Neurophysiol 1995;97:73-6.

Kohno M, Takahashi H, Yagishita A, Tanabe H."Disproportion theory" of the cervical spine and spinal cord in patients with juvenile cervical flexion myelopathy. A study comparing cervical magnetic resonance images with those of normal controls. Surg Neurol 1998;50:421-30.

9. Khandelwal D, Bhatia M, Singh S, Shukla G, Goyal V, Srivastava T, et al. Widespread electromyographic abnormalities in patients with monomelic amyotrophy: A detailed EMG study. Electromyogr Clin Neurophysiol 2005;45:363-7.

10. Khandelwal D, Bhatia M, Singh S, Shukla G, Goyal V, Srivastava T, et al. Threshold intensity and central motor conduction time in patients with monomelic amyotrophy: A transcranial magnetic stimulation evaluation. Electromyogr Clin Neurophysiol 2004;44:357-60

11. Kaji R. Electrodiagnosis of neuromuscular diseases - a syndrome of monomelic amyotrophy with spinal hemiatrophy, anti-GM1 antibodies and abnormal F-waves. Rinsho Shinkeigaku 1994;34:1272-5

12. Thomas FP, Trojaborg W, Nagy C, Santoro M, Sadiq SA, Latov N, et al. Experimental autoimmune neuropathy with anti-GM1 antibodies and immunoglobulin deposits at the nodes of Ranvier. Acta neuropathol Berl 1991;82:378-83.

13. Endo T, Scott DD, Stewart SS, Kundu SK, Marcus DM. Antibodies to glycosphingolipids in patients with multiple sclerosis and SLE. J Immunol 1984 ;132:1793-7.

14. Pestronk A, Adams RN, Clawson L, Cornblath D, Kuncl RW, Griffin D, et al. Serum antibodies to GM1 ganglioside in amyotrophic lateral sclerosis. Neurology 1988;38:1457-61.

15. Chapman J, Sela BA, Wertman E, Michaelson DM. Antibodies to ganglioside GM1 in patients with Alzheimer's disease. Neurosci Lett 1988;86:235-40.

16. Latov N, Koski C, Walicke PA. Guillain-Barre syndorome and parentral gangliosides. Lancet 1991;338:378-383.

Accepted on 14-08-2006

Source of Support: Nil, Conflict of Interest: None declared. 